\title{
Erysipelothrix rhusiopathiae
}

National Cancer Institute

\section{Source}

National Cancer Institute. Enysipelothrix rhusiopathiae. NCI Thesaurus. Code C86377.

A species of facultatively anaerobic, Gram positive, rod shaped bacterium assigned to the phylum Firmicutes. This species is nonsporulating, not acid fast, decolorizes rapidly so may appear Gram negative, alpha-hemolytic and catalase and oxidase negative. E. rhusiopathiae is found in a variety of host animals including fish and swine as well as in feces and sewage. It is pathogenic in a variety of organisms including domestic swine and humans, causing both cutaneous and septicemic infections and the disease swine erysipelas. 